\title{
O USO DE PIRÂMIDES DE VEGETAÇÃO PARA A REPRESENTAÇÃO GRÁFICA DA MATA CILIAR DO CÓRREGO ÁGUA PEQUENA, REALEZA, PR.
}

\author{
Karine Bueno Vargas ${ }^{1}$ \\ Thalita Dal Santo ${ }^{2}$ \\ Deise Tatiane Bueno Miola ${ }^{3}$
}

\begin{abstract}
RESUMO
O córrego Água Pequena, está localizado no sudoeste do Paraná, sob domínio da Mata Atlântica, sendo a principal fisionomia a Floresta Ombrófila Mista, determinada pela presença da espécie Araucária angustifólia. A aplicação do estudo fitossociológico nessa área teve como objetivo analisar as características mais marcantes da área e suas condições atuais, utilizando a técnica de representação gráfica das pirâmides de vegetação. O levantamento de campo foi realizado de acordo com a metodologia de Braun-Blanquet (1979) e Bertrand (1966), gerando uma análise comparativa da evolução da vegetação da área. Desta forma, tal estudo fornece informações quali-quantitativas localizadas espacial e temporalmente, como os índices de abundância, frequência, dominância e diversidade, além do chamado valor de importância das espécies, representando a vegetação dos pontos coletados verticalmente.
\end{abstract}

PALAVRAS-CHAVE: fitossociologia, pirâmides de vegetação, biogeografia.

\section{THE VEGETATION PYRAMIDS USE FOR GRAPHIC REPRESENTATION OF MATA CILIARY OF ÁGUA PEQUENA RIVER, REALEZA, PR.}

\begin{abstract}
The Água Pequena river, is located in the southwest of Paraná, in the Atlantic Forest domain, where it predominates the physionomy the Araucaria Forest, determined by the presence of the specie Araucaria angustifolia. The phytosociological study in this área aimed to analyze the most striking features of the area and their current conditions using the graphical representation technique of vegetation pyramids. The field survey was carried out according to the methodology of BraunBlanquet (1979) and Bertrand (1966), generating a comparative analysis of the evolution of the vegetation of the area. Thus, this study provides qualitative and quantitative information located in space and time, as the indices of abundance, frequency, dominance and diversity, beyond the call importance value of species, representing the vegetation of points collected vertically.
\end{abstract}

KEY-WORDS: Phytosociological study, Vegetation pyramids, Biogeography.

\footnotetext{
${ }^{1}$ Doutoranda em Geografia. Universidade Estadual de Maringá. E-mail: karibvargas@yahoo.com.br

${ }^{2}$ Mestranda em Geografia. Universidade Estadual de Maringá. E-mail: thadalsanto@hotmail.com

${ }^{3}$ Mestre em Ecologia Conservação e Manejo de Vida Silvestre. Faculdade de Pará de Minas. E-mail: deise.miola@fapam.edu.br
} 


\section{USO DE LAS PIRÁMIDES DE VEGETACIÓN EN LA REPRESENTACIÓN GRÁFICA DE MATA CILIAR EM LO RÍO ÁGUA PEQUENA, REALEZA, PR.}

RESUMEN: La río Água Pequena esta situado en el suroeste de Paraná, en el dominio de la Mata Atlántica , la cara principal del Bosque Ombrofila Mixta, determinada por la presencia de la especie Araucaria angustifólia. La aplicación del estudio fitosociológico en este ámbito es analizar las características más llamativas de la zona y sus condiciones actuales mediante la técnica de representación gráfica de las pirámides de vegetación, que se han basado en los estudios de vegetación realizados en el campo, utilizando la metodología de Braun-Blanquet (1979) y Bertrand (1966), lo que generó en análisis comparativa de la evolución de la vegetación de la zona. Por lo tanto, este estudio proporciona información cualitativa y cuantitativa ubicada en el espacio y el tiempo, como los índices de abundancia, frecuencia, dominancia y diversidad, más allá del valor de importancia de llamadas de las especies, que se utiliza como subsidios para acciones locales de gestión ambiental, así como regalos metodología que se propone para su aplicación en otras áreas.

PALABRAS CLAVE: fitossociologia, pirámides de vegetación, biogeografía .

\section{INTRODUÇÃO}

Para o sucesso de qualquer plano de recuperação de áreas degradadas, manejo florestal e preservação de unidades de conservação, são necessárias avaliações preliminares da estrutura e funcionamento do ambiente. Barbosa et al., (1989) e Kageyama et al., (1992) ressaltam em suas pesquisas a importância que os estudos quali-quantitativos, aliados a estudos fitogeográficos, fitossociológicos e fenológicos, possuem na elaboração de modelos de regeneração ecológica.

Os estudos fitossociológicos são uma ótima opção para obtenção de dados relativos a composição, estrutura, funcionamento, dinâmica, histórico, distribuição e relações ambientais das comunidade vegetais, apoiados pela taxonomia vegetal, fitogeografia e ciências florestais. Segundo Martins (1989), os estudos fitossociológicos envolvem as interrelações de espécies vegetais dentro da comunidade vegetal no espaço e no tempo, relacionados à caracterização das etapas sucessionais em que as espécies estão presentes, seja na regeneração natural ou em atividades planejadas para uma área degradada, ainda apontam possibilidades de associações inter-específicas e de estudos em nível específico sobre agressividade, propagação vegetativa, ciclo de vida e dispersão.

No âmbito desses estudos, a construção de pirâmides é uma metodologia importante de avaliação da vegetação, pois representam de forma gráfica a 
estruturação vertical de uma formação vegetal e oferecem uma visão expressiva do tapete vegetal, sendo possível classificar as formações segundo o nível de recobrimento, fazendo intervir o número de estratos e a concorrência existente entre as espécies (PASSOS, 1998). O uso das pirâmides como método de análise permite também representar a concorrência existente nos diferentes estratos vegetacionais, os efeitos da ação do homem sobre a floresta e ainda o papel da topografia e condições pedológicas sobre ela, dando uma melhor ideia das relações entre vegetação e a erosão biológica. Este é um fator ecológico permanente que, associado a outros fenômenos, torna-se um elemento fundamental da repartição e da dinâmica do tapete vegetal, sendo um fator de mobilidade (PASSOS, 1998).

Nesse sentido, o presente trabalho objetivou avaliar por meio da construção de pirâmides de vegetação a Área de Preservação Permanente (APP) do córrego Água Pequena, no município de Realeza, sudoeste do estado do Paraná (Figura 1). Esse corpo d'água encontra-se inserido na zona urbana do município e sofre diferentes impactos antrópicos advindos das atividades realizadas em seu entorno. Sua área de preservação permanente encontra-se sob domínio da Mata Atlântica, sendo sua fisionomia principal a Floresta Ombrófila Mista, delimitada exclusivamente pela presença do Pinheiro do Paraná (Araucária angustifolia) (IBGE 2012).

Figura 1. Localização e Pontos de Coleta do Córrego Água Pequena.

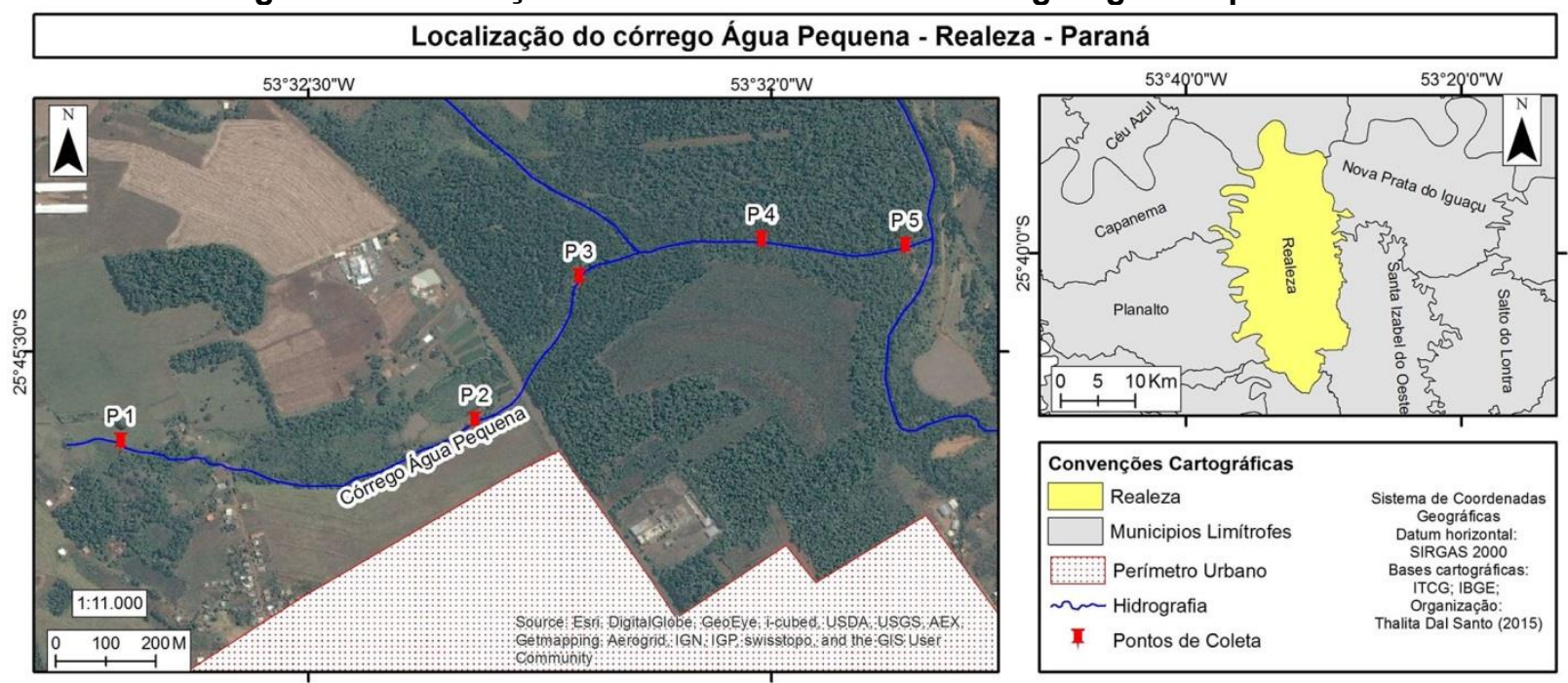

Fonte: autoras (2015). 
A escolha do córrego Água Pequena para a realização desse estudo deve-se ao fato de que sua situação ambiental é semelhante a da grande maioria dos corpos d'água da região. A partir do levantamento das características florísticas, fitossociológicas e biogeográficas de sua APP pretendeu-se avaliar a evolução e a dinâmica da vegetação do córrego, gerando dados que possam subsidiar ações de recuperação e conservação das matas ciliares da região. As matas ciliares ou florestas ripárias são as formações arbóreas localizadas na margem dos corpos de água que possuem importância relevante na manutenção do equilíbrio do ecossistema aquático (SOUZA, 1999). A destruição destes ambientes traz consequências irreparáveis, como a perda da biodiversidade local e regional; o aumento da erosão do solo e a perda de sua camada biológica; o assoreamento de rios, lagos e reservatórios (Joly et al., 2000) e a diminuição da qualidade da água.

\section{METODOLOGIA}

Para a realização do estudo fitossociológico foram demarcados cinco pontos de coleta da mata ciliar (Figura 1) na APP do córrego Água Pequena, que possui uma extensão de aproximadamente $3 \mathrm{~km}$. Em todos os pontos foram delimitadas parcelas circulares de $10 \mathrm{~m}$ de raio $\left(314 \mathrm{~m}^{2}\right)$, totalizando $1570 \mathrm{~m}^{2}$ de área amostrada. Nessas parcelas foram preenchidas as fichas biogeográficas conforme $o$ modelo proposto por Bertrand (1966), as quais auxiliaram para a aplicação da análise fitossociológica proposta por Braun-Blanquet (1979). A mesma avaliou o grau de cobertura do solo e a distribuição das espécies, utilizando os parâmetros de abundância, dominância e sociabilidade.

Para a avaliação do grau de cobertura do solo, ocupado por cada estrato ou andar de vegetação e seus hábitos, tais como: emergentes, arbóreo superior, arbóreo inferior, arbustivo, herbáceo e epifítico, utilizou-se novamente a metodologia de Braun-Blanquet (1979), adotando os seguintes parâmetros: 5 - de $75 \%$ a 100\%; 4 - de $50 \%$ a $75 \% ; 3$ - de $25 \%$ a $50 \% ; 2$ - de $10 \%$ a $25 \%$ de cobertura. O valor 1 foi utilizado quando a planta é abundante, porém com valor de cobertura abaixo, não superando $10 \%$ e + para alguns raros exemplares.

Com relação a sociabilidade que indica o modo de agrupamento das plantas também adotou-se os critérios de Braun-Blanquet (1979), sendo: 5 para populações 
continuas (manchas densas); 4 para o crescimento em pequenas colônias (manchas densas pouco extensas); 3 para espécies que crescem em grupos; 2 para agrupamentos vegetacional entre 2 ou 3 indivíduos; 1 para indivíduos isolados; + para planta rara ou isolada.

A partir da análise dos dados foram construídas manualmente 5 pirâmides de vegetação, uma para cada parcela, seguindo a metodologia de Passos (1998), que consiste em desenhar sobre um papel milímetro um segmento de reta horizontal de $10 \mathrm{~cm}$ de comprimento. Sobre esta base e no seu centro, ergue-se, perpendicularmente, o eixo da pirâmide. Dispõem-se os estratos de vegetação simetricamente em relação ao eixo, considerando sua ordem normal de superposição, de seu índice de recobrimento (abundância-dominância $1=1 \mathrm{~cm}, 2$ = $2 \mathrm{~cm}, 5=5 \mathrm{~cm})$. A espessura de cada estrato, representado na pirâmide, está determinada arbitrariamente, de modo a facilitar as interpretações biogeográficas: estrato $1=0,5 \mathrm{~cm}$, estrato 2 e $3=1 \mathrm{~cm}$, estrato $4=1,5 \mathrm{~cm}$, estrato $5=2 \mathrm{~cm}$. A construção da pirâmide é concluída com outras informações: Na base, colocam-se as informações relativas à serrapilheira (espessura, superfície coberta), pois esta joga um papel essencial no equilíbrio da formação. Abaixo desta, indica-se o tipo de solo (espessura, perfil simplificado) e a rocha mãe. Para se ter uma imagem precisa das condições estacionais (inclinação, insolação, 35 escoamento...), oscila-se a pirâmide de um ângulo igual ao valor da inclinação da vertente sobre a qual se encontra a formação; enfim, as flechas indicam a dinâmica dos diferentes estratos.

Dentre os materiais utilizados para tal estudo, lançou-se mão do material cartográfico já existente e imagens de satélite, utilizados para localização, caracterização da área e confecção de mapas. Também foram realizadas visitas in loco para a coleta de dados.

\section{RESULTADOS E DISCUSSÃO}

O primeiro ponto amostrado está localizado a $100 \mathrm{~m}$ da nascente, nas coordenadas 5332'42" W e $25^{\circ} 45^{\prime} 36^{\prime \prime} \mathrm{S}$, possuindo uma altitude média de $490 \mathrm{~m}$ (Figura 2). A mata ciliar deste local é espaçada, e a nascente a montante encontrase sem mata ciliar. Analisando a dinâmica dos estratos através da pirâmide de vegetação, foi verificado que o estrato herbáceo rasteiro está recoberto por 
gramíneas exóticas, apresentado uma dinâmica regressiva, sendo que os demais estratos apresentam-se em estágio de progressão, tendo como tendência o estabelecimento de novos indivíduos arbóreos advindos de remanescentes florestais próximos. A camada herbácea rasteira tenderá a sofrer regressão, pela falta de luminosidade, dessa forma o aumento da camada arbórea acarretará num aumento da serrapilheira e do húmus.

Em relação aos índices de abundância e dominância, que observa o grau de cobertura por plantas na paisagem, seguidas pela metodologia de Blanquet (1979), verificou-se que a serrapilheira e o húmus está no nível 3 , o que significa que o estrato recobre entre $25 \%$ e $50 \%$ do solo. Seguida pelo estrato herbáceo rasteiro que tem um recobrimento no nível 5 que equivale a $75 \%$ a $100 \%$ de cobertura, destacando-se as brachiarias. O estrato subarbustivo está no nível 2, tendo uma cobertura de $10 \%$ a $25 \%$, sendo destaque a espécie Senecio brasilienses, popularmente conhecida como Maria-Mole. Vale ressaltar que está planta está num alto índice de progressão, tanto nas áreas de pastagens, quanto na mata ciliar.

O estrato arbustivo também encontra-se no nível 1, tendo um valor de cobertura baixo, não superando a 10\%. No estrato arborescente ganha destaque a Bambusa sp, no entanto, o nível do estrato é 3, havendo um recobrimento de $25 \%$ e $50 \%$. E por fim, o estrato arbóreo encontra-se no nível 2, cobrindo entre $10 \%$ a $25 \%$. Destaca-se a espécie Luehea divaricata, popularmente conhecida como açoitacavalo, sendo um indivíduo nativo, com uma média de $15 \mathrm{~m}$ de altura, e ele está recoberto por vários tipos de epífitas as quais não foram classificadas na tabela.

Para avaliar a sociabilidade, a metodologia de BRAUN (1979) indica o modo de agrupamento das plantas. Sendo verificado que o estrato herbáceo rasteiro possui uma população contínua de branquiárias estando no nível 5 . O estrato subarbustivo está no nível 3, havendo crescimento em grupos, o arbustivo está no nível 1, apresentando plantas isoladas. O estrato arborescente está no nível 4 e apresenta crescimento em pequenas colônias. E por fim o arbóreo que também apresenta indivíduos isolados. 
Figura 2: Pirâmide de Vegetação do Ponto 1

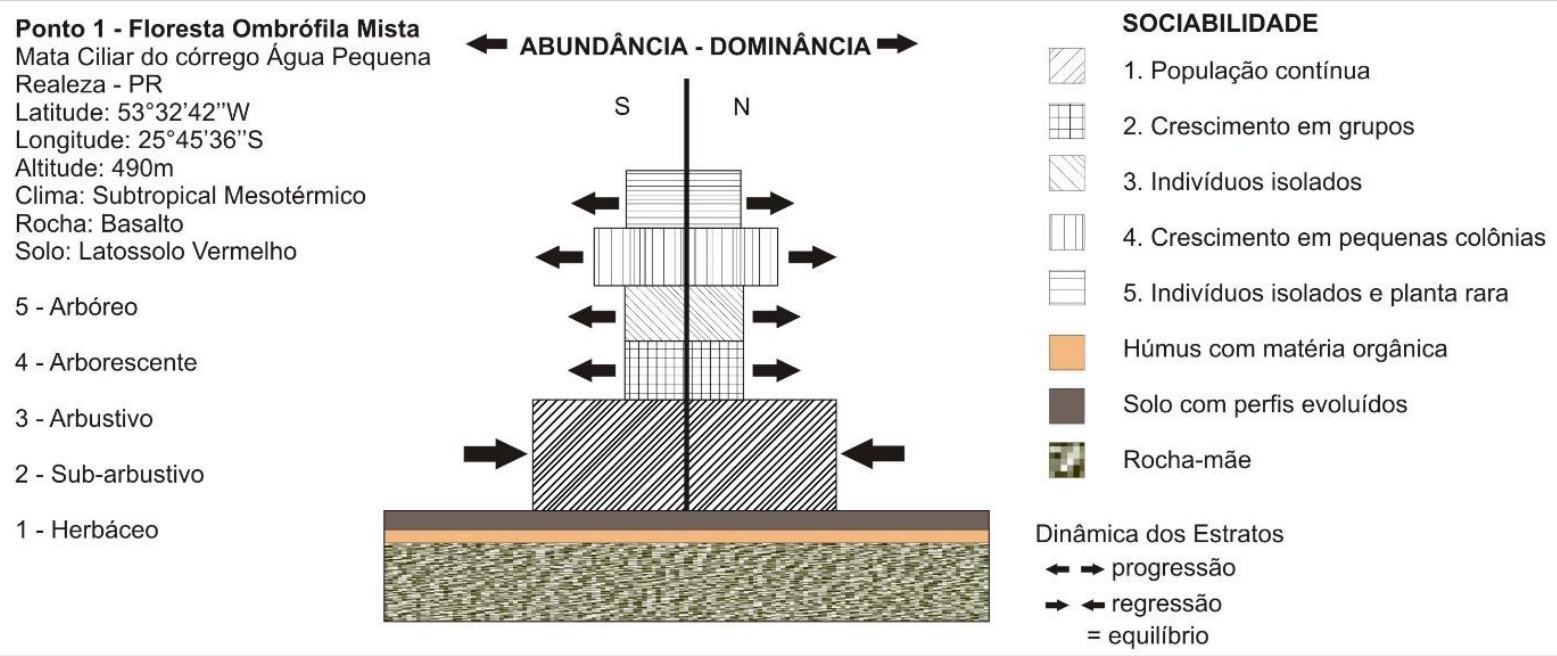

Fonte: modificado de Vargas (2009).

O ponto 2 está localizado nas coordenadas $53^{\circ} 32^{\prime} 30^{\prime \prime} \mathrm{W}$ e $25^{\circ} 45^{\prime} 35^{\prime \prime} \mathrm{S}$, possuindo uma altitude média de $470 \mathrm{~m}$, estando próxima a PR 182 (Figura 3). Esta área encontra-se muito impactada, apresentando solos desnudos em alguns pontos, e está em estágio inicial de uma sucessão secundária, com alguns remanescentes antigos e todos os estratos em relação a sua dinâmica estão em estágio progressivo.

Em relação aos índices de abundância e dominância, a serrapilheira e o húmus está cobrindo entre $10 \%$ e $25 \%$ do solo. O herbáceo rasteiro tem um grau de cobertura entre $25 \%$ e $50 \%$. O estrato sub-arbustivo está no nível 4 , com um grau de cobrimento entre $50 \%$ e $75 \%$. O estrato arborescente está no nível 2, possuindo um grau de cobertura de $10 \%$ e $25 \%$. E o estrato arbóreo está no mesmo nível, estando entre $10 \%$ e $25 \%$ de cobertura.

Analisando a sociabilidades, verificou-se que o estrato herbáceo rasteiro está no nível 5 , possuindo uma população contínua, destacando-se o Panicum maximum. $O$ estrato sub-arbustivo está no nível 4, havendo o crescimento das espécies em pequenas colônias como é o caso da Impatiens walleriana nas encostas do córrego. O estrato arbustivo também está no nível 4, possui manchas densas pouco extensas destacando-se uma espécie não identificada da família Piperaceae. O estrato arboresceste está no nível 3, havendo crescimento das espécies em pequenos grupos. 
Figura 3: Pirâmide de Vegetação do Ponto 2

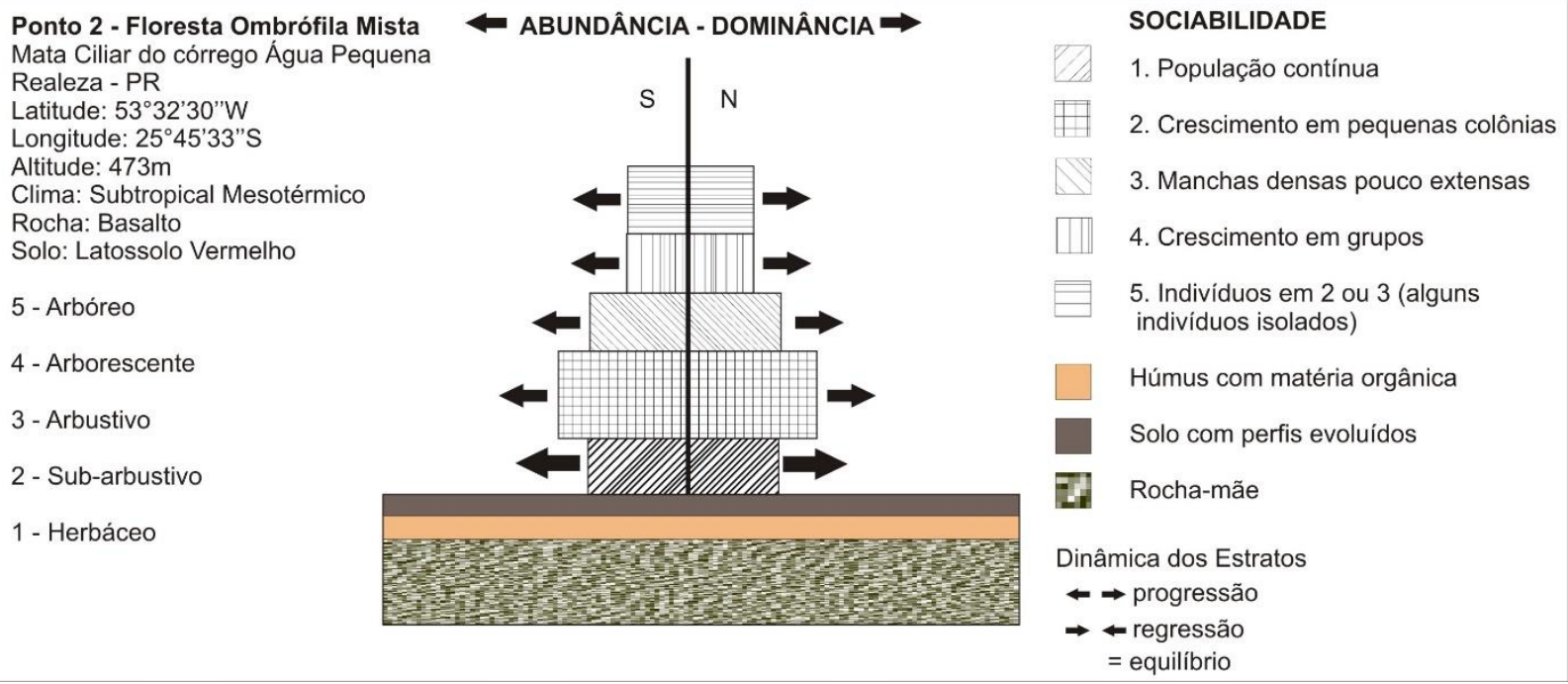

Fonte: modificado de Vargas (2010).

O ponto 3 está localizado nos conhecidos "Pinheirinhos da Cazaca", do lado direito da rodovia PR 182, nas coordenas $53^{\circ} 32^{\prime} 13^{\prime \prime}$ W e $25^{\circ} 45^{\prime} 25^{\prime \prime}$, possuindo uma altitude média de 450m, mais especificadamente na média vertente do córrego Água Pequena (Figura 4). Mesmo sendo um dos pontos mais preservados, no entanto, ainda há evidência de impactos antrópicos. Sua vegetação secundária é bem desenvolvida, resultado de um plano de manejo na área na década de 70.

Em relação a dinâmica dos estratos pode-se observar que a serrapilheira encontra-se em equilíbrio, no entanto o herbáceo rasteiro está em regressão, devido à falta de luminosidade pois é coberto por árvores maiores, e o restante dos estratos estão em estágio de equilíbrio.

Em relação à abundância e dominância do ponto 3, pode-se verificar que a serrapilheira/húmus está em ótimo estado, cobrindo entre $75 \%$ e $100 \%$ do solo, já o estrato herbáceo rasteiro está no nível 5 também, no entanto ele tende a regredir, o sub-arbustivo, está no nível 2, cobrindo entre $10 \%$ a $25 \%$ da área. 0 estrato arbustivo está no nível 1, tendo a mesma Piperaceae como planta abundante, no entanto, não ultrapassa a $10 \%$ da cobertura da área. O estrato arborescente é o menor de todos, havendo alguns raros exemplares. O estrato arbóreo encontra-se no nível 5, com grau de cobertura de 75\% a 100\% destacando- 
se as Araucárias, as quais somente nesta parcela, foram contabilizadas 15 indivíduos adultos.

$\mathrm{Na}$ análise da sociabilidade do ponto 3, pode-se verificar que o estrato herbáceo rasteiro encontra-se no nível 5, havendo uma população continua de Panicum maximum e Polypodium Adiantum sp. O estrato sub-arbustivo está no nível 3, havendo um crescimento das espécies em grupos como é o caso da Tibouchinia $s p$. O estrato arbustivo também está no nível 3 e o arborescente no 2, no qual as espécies estão agrupadas em 2 ou 3. E por fim, o estrato arbóreo apresenta-se com grande destaque, estando no nível 5, havendo uma população continua de espécies como Araucaria angustifolia, Ocotea sp, Eugenia sp entre outras.

Figura 4: Pirâmide de Vegetação do Ponto 3

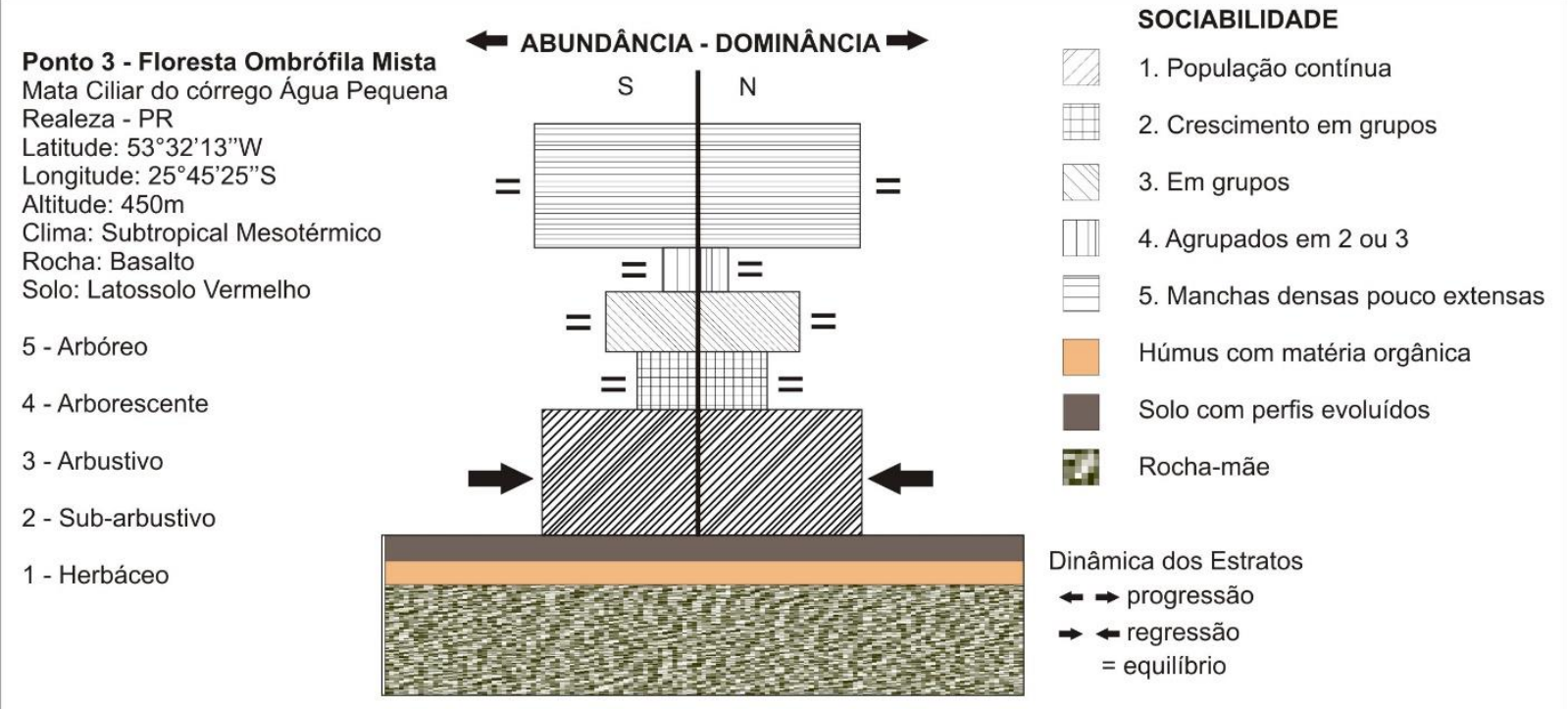

Fonte: modificado de Vargas (2010).

O ponto 4 (Figura 5), está localizado a montante da foz do córrego, estando nas coordenadas $53^{\circ} 32^{\prime} 00^{\prime \prime} \mathrm{W}$ e $25^{\circ} 45^{\prime} 22^{\prime \prime} \mathrm{S}$, possuindo uma altitude média de 435m. A mata ciliar encontra-se sobre um vale em V, ou seja, um vale esculpido pelo córrego, em fase ativa de erosão. Encontra-se pontos de desmatamento neste setor, e a serrapilheira persiste, mais não existe estrato arbóreo contínuo. Em relação a dinâmica dos estrato,s verificou-se que a serrapilheira/húmus está em regressão, no entanto todos os outros estão em estado de progressão.

Avaliando o grau de abundância e dominância do ponto 4, verificou-se que a serrapilheira/húmus está no nível 5, cobrindo $75 \%$ e $100 \%$ do solo. O estrato herbáceo rasteiro e sub-arbustivo estão no nível 1, sendo abundante, porém com 
valor de cobertura baixo, não superando a 10\%. Os estratos arbustivos e arborescentes estão no nível 2 cobrindo entre $10 \%$ a $25 \%$ da cobertura do solo. Já o estrato arbóreo encontra-se no nível 3, cobrindo entre $25 \%$ a 50\% da área.

A partir da sociabilidade pode-se verificar que 0 estrato herbáceo rasteiro está no nível 1, apresentando indivíduos isolados como é o caso do Panicum maximum. O estrato sub-arbustivo está no nível 3, havendo crescimentos em grupos das espécie Impatiens walleriana, principalmente nas encostas do córrego, nas parte mais úmidas do terreno. O estrato arbustivo está no nível 5, havendo populações continuas das espécies Piper amalago e Polypodium. O estrato arborescente está no nível 4, havendo crescimento em pequenas colônias, sendo manchas densas pouco extensas de Eugenia sp, Mimosa sp e Bambusa sp. Dessa forma o estrato arbóreo encontra-se no nível 2 , havendo um agrupamento em 2 ou 3 individuos, tendo como destaque as espécies nativas Anadenanthera $\begin{array}{llll}\text { colubrina, } & \text { Cedrela } & \text { fissilis } & \text { Citrus }\end{array}$ aurantium.

Figura 5: Pirâmide de Vegetação do Ponto 4
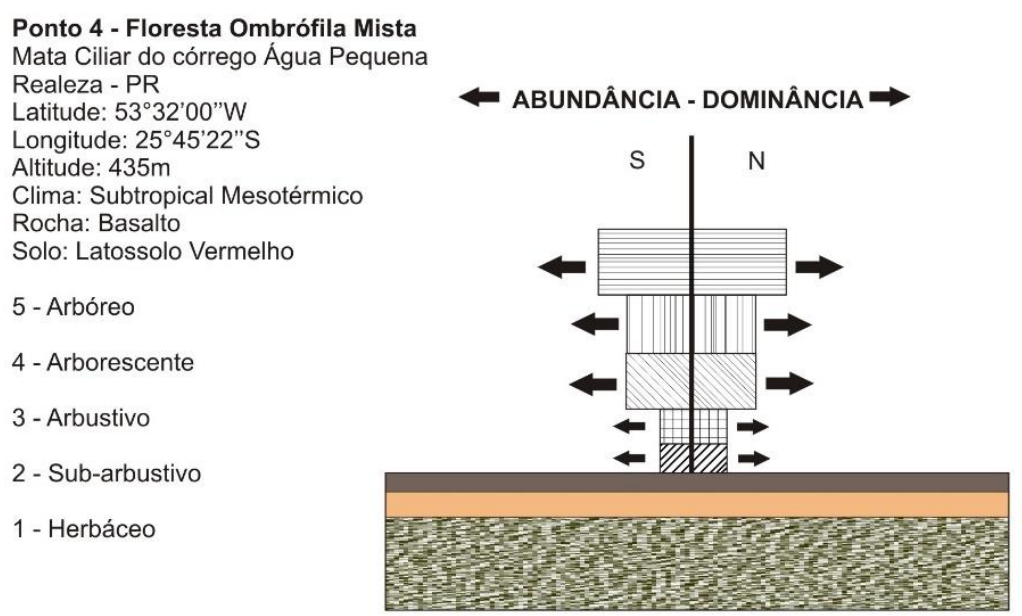

Fonte: modificado de Vargas (2010).

\section{SOCIABILIDADE}

1. Indivíduos isolados

2. Crescimento em grupos

3. Manchas densas

4. Manchas densas pouco extensas

5. Agrupados em 2 ou 3

Húmus com matéria orgânica

Solo com perfis evoluídos

\# Rocha-mãe

Dinâmica dos Estratos

$\leftarrow$ progressão

$\rightarrow \leftarrow$ regressão

= equilibrio

O ponto 5, está localizado acima da gruta Nossa Senhora de Lurdes, sendo a foz do córrego Água Pequena, o qual irá unir-se ao Rio Sarandi. As coordenadas da área são $53^{\circ} 31^{\prime}$ '51" W e 25 45' 23" S, estando numa altitude de $435 \mathrm{~m}$ (Figura 6). A vegetação secundária está bem desenvolvida, no em tanto há indícios de interferências antrópica. A dinâmica dos estratos variam de equilibrada nos estratos 
inferiores como herbáceo rasteiro, sub-arbustivo e arbustivo. E nos superiores arborescente e arbóreo ela é considerado como estando em estágio progressivo. Em relação a abundância e dominância verificou-se que a serrapilheira/húmus está no nível 5, tendo um grau de cobertura do solo entre $75 \%$ e 100\%. O estrato herbáceo rasteiro está no nível 1, apresentando apenas alguns raros exemplares de Panicum maximum. O sub arbustivo está no nível 2, cobrindo entre $10 \%$ a $25 \%$ do solo. O arbustivo está no nível 1, tendo o Piper amalago como planta abundante, porém ele possui baixo valor de cobertura. O estrato arborescente também está no nível 2 cobrindo entre $10 \%$ a 25\%, no entanto a Bambusa sp. é a principal espécie desse estrato. E por fim o estrato arbóreo tendo um maior grau de cobertura, cobrindo entre $25 \%$ a $50 \%$ da área, destacando-se com maior grau de cobertura o Schinus therenbitifolia.

Com relação à sociabilidade do ponto 5, verificou-se que o estrato herbáceo rasteiro está no nível 1, apresentando indivíduos isolados. No estrato sub arbustivo e arbustivo estão no nível 3, havendo crescimento em grupos das espécies, destacando-se o Piper amalago, Impatiens walleriana e Polypodium. $O$ estrato arborescente está no nível 4, havendo manchas densas pouco extensas e o estrato arbóreo está no nível 2, possuindo indivíduos agrupados em 2 ou 3.

Figura 6: Pirâmide de Vegetação do Ponto 5

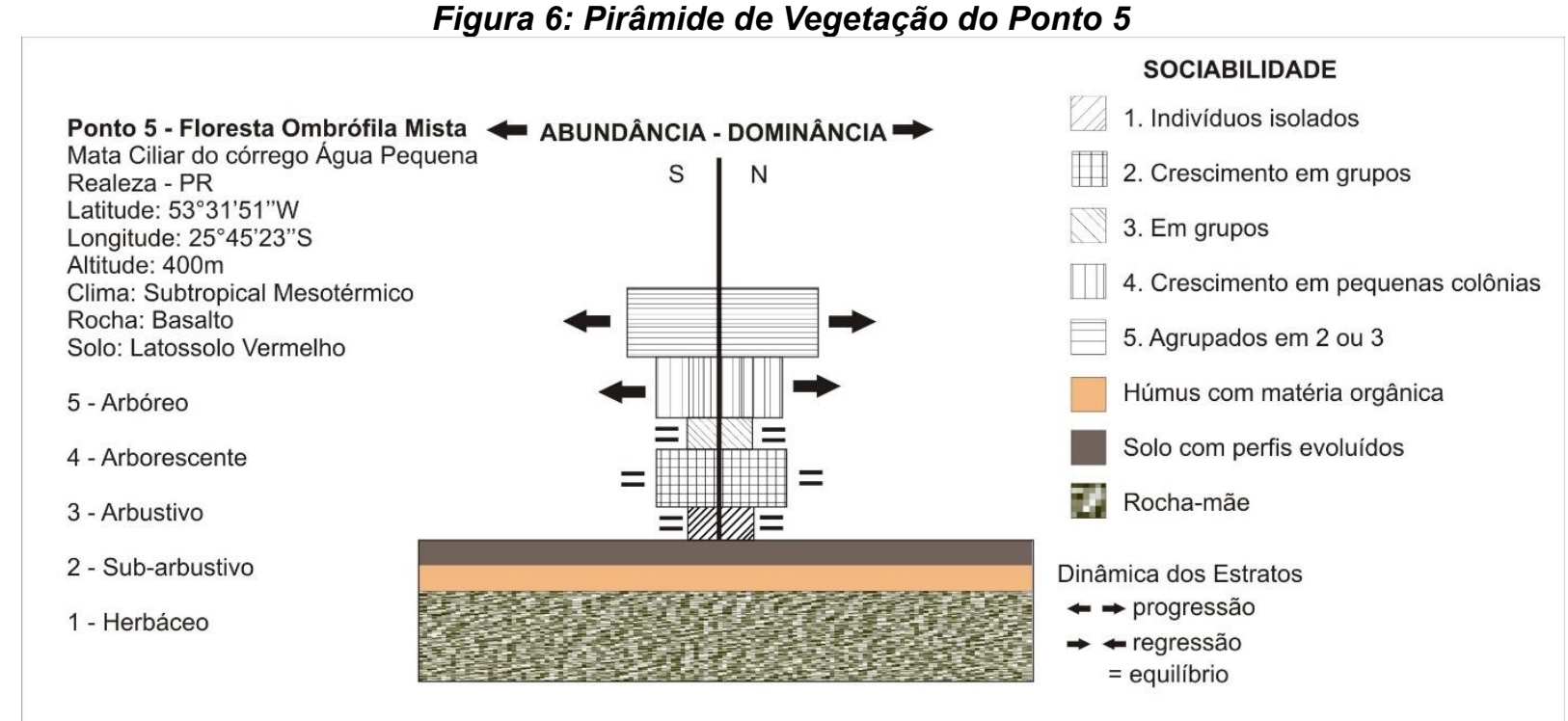

Fonte: modificado de Vargas (2010). 
A intensa degradação que a mata ciliar do córrego Água Pequena sofreu, resultou numa paisagem bastante fragmentada, ocasionando além da perda de habitat, a extinção e o isolamento das populações, que pode levar a um o empobrecimento genético; perda da biodiversidade, erosão dos solos e assoreamento, além de distúrbios no regime dos rios.

Verificou-se a partir do estudo fitossociológico que houve variações expressivas na mata ciliar, tanto em relação à diversidade das espécies, quanto ao grau de cobertura vegetal. Um dos fatores por essas assimetrias na paisagem são os diferentes tipos de uso de solo, pois no ponto 1 e 2 , tais matas foram abertas para pastoreio, e mais recentemente processos de urbanização incidem na área, apresentando uma mata ciliar insuficiente para manter as funções ecológicas.

Nos pontos 3, 4 e 5 a vegetação se mantém mais preservada por abranger áreas de reserva legal, mas ainda assim ocorrem diferenças em relação aos estratos, o que fica visível ao observamos as pirâmides de vegetação. Isso se deve à retirada ilegal de madeira, ao desmatamento para abertura de pastagens e também pelo despejo de efluentes de uma indústria de laticínios local, o que afetou a biodiversidade e a vegetação das encostas.

Para a revitalização da mata ciliar ao longo do córrego é necessário planejamento de atividades de manejo da Floresta Ombrófila Mista, contemplando aspectos que interajam, desde a configuração da paisagem, o diagnóstico e monitoramento dos elementos de flora e fauna e suas inter-relações com o meio físico, avaliação socioeconômica, envolvimento com a sociedade local, criação e aplicação de políticas públicas e o desenvolvimento de diferentes técnicas de manejo (BORSOI, 2004; BRITEZ, 2007; SERVIÇO FLORESTAL BRASILEIRO, 2010)

De acordo com o trabalho de Britez (2007), o qual descreve os aspectos ambientais a serem considerados na restauração da Floresta com Araucária no Estado do Paraná, o processo de restauração inicia-se pela análise da paisagem, com a definição de unidades geográficas baseadas em componentes ambientais (clima, água, geomorfologia, fauna, flora, uso da terra) e socioeconômicos (infraestrutura, demografia, estrutura fundiária e outros), onde estas informações podem ser armazenadas e analisadas em um Sistema de Informações Geográficas (SIG), que definirá os locais de intervenção ambiental. 
De acordo com o autor supracitado, a conservação da floresta com Araúcarias deve estar associada a uma abordagem metodológica que assegure a proteção de extensões mais abrangentes da paisagem, de forma a assegurar efetivamente a manutenção de comunidades ecologicamente viáveis a longo prazo, e não "ilhas" que, isoladas, sofrem uma deterioração progressiva de seus ambientes, na maioria das vezes a partir das bordas, face à pressão antrópica e às perturbações naturais. Tendo em vista 0 atual estado de degradação da mata ciliar do córrego Água Pequena, e visando à conservação da biodiversidade, é imprescindível estabelecer um programa de conservação in situ dos remanescentes florestais em estágio avançado de sucessão, uma vez que estes são os relictos das florestas primitivas. Estes remanescentes são os que sofrem maior pressão e, não conservá-los, significa assumir perdas irreversíveis que afetarão a qualidade e a disponibilidade dos recursos hídricos e, posteriormente, os processos de restauração da floresta. Destaca-se que o primeiro passo para a recuperação do local deve ser o isolamento da área dos fatores de perturbação. O cercamento da área de preservação permanente do córrego Água Pequena irá limitar a atividade agrícola e impedir o acesso de animais de grande porte e o consequente pisoteio do solo. Ao evitar dar continuidade à degradação, os fatores ecológicos podem voltar a se restabelecer na área, promovendo a regeneração natural de espécies (MARTINS, 2012).

\section{CONSIDERAÇÕES FINAIS}

Com a obtenção dos dados fitossociológico da mata ciliar do córrego Água Pequena, verificou-se que a identificação da composição florística, estrutura da vegetação por estratos, sua dinâmica, e os índices de abundância/dominância e sociabilidade são dados essenciais para a construção de um plano de manejo, pois estes dados apresentam as áreas mais impactadas e os estágios sucessionais as quais elas sem encontram.

As pirâmides de vegetação serviram como uma ótima técnica de representação gráfica, mostrando as características do estratos em escala vertical. Corroborando com Passos (2000), ressalta-se que as pirâmides expressam a 
evolução da vegetação e as condições biogeográficas que não são possíveis identificar pela teledetecção por sensores remotos, como os estratos e as espécies, traduzindo perfeitamente a concorrência entre as espécies, pois os estratos superiores sufocam as plantas dos estratos inferiores e muitas vezes as áreas desmatadas são posteriormente invadidas por espécies arbustivas as quais recobrem o solo, protegendo-o contra a erosão.

Para a aplicação de estratégias de restauração no córrego Água Pequenas estas devem levar em consideração as especificidades ambientais da área. O estudo fitossociológico realizado pode ser utilizado em um futuro plano de manejo da área, assim como, a metodologia proposta no presente artigo pode ser aplicada em demais áreas, a fim de compreender os estágios sucessionais e a evolução vegetacional de diferentes ecossistemas, já que a aplicação dos métodos apresentandos são ainda bastante restritos no meio cientifico.

\section{REFERÊNCIAS}

BARBOSA, D. C. A.; ALVES, J. L. DE H.; PRAZERES, S. DE M. ; ASTENILSEN M. ; PAIVA, A. M. A. Dados fenológicos de 10 espécies arbóreas de uma área de caatinga ( Alagoinha-PE). Acta Botânica Brasílica,1989.

BERTRAND, G. Pour une étude géographique de la vegetation. R.G.P.S-O, t. XXXVII, Toulouse, 1966.

BRAUN-BLANQUET, J. Fitosociologia. Bases para el estudio de las comunidades vegetales. ed. Blume, Madrid,1979.

BRITEZ, R. M. de. Aspectos ambientais a serem considerados na restauração da Floresta com Araucária no Estado do Paraná. Pesquisa Florestal Brasileira. Colombo, n.55, p. 37-43, jul./dez. 2007.

BORSOI, G. A. Subsídios para o manejo de uma Floresta Ombrófila Mista em estágio avançado de regeneração natural. Tese de Doutorado. Universidade Federal de Santa Maria. Santa Maria, 2004.

INSTITUTO BRASILEIRO DE GEOGRAFIA E ESTATÍSTICA - IBGE. Manual Técnico da Vegetação Brasileira. Manuais técnicos em geociências. Rio de Janeiro, 2012.

JOLY, C.A.; SPIGOLON, J.R.; LIEBERG, S.A.; SALIS, S.M.; AIDAR, M.P.M.; METZGER, J.P.W.; ZICKEL, C.S.; LOBO, P.C.; SHIMABUKURO, M.T.; MARQUES, M.C.M.; SALINO, A. Projeto JacaréPepira - O desenvolvimento de um modelo de recomposição da mata ciliar com base na florística regional. In: RODRIGUES, R.R.; LEITÃO FILHO, H.F. (Eds.) Matas ciliares: conservação e recuperação. São Paulo: EDUSP, 2000. cap. 15.3, p. 271-278.

KAGEYAMA, P.Y.; FREIXÊDAS, V.M.; GERES, W.L.A.; DIAS, J.H.P.; BORGES, A.S. Consórcio de espécies nativas de diferentes grupos sucessionais em Teodoro Sampaio, SP. In: CONGRESSO 
NACIONAL SOBRE ESSÊNCIAS NATIVAS, 2, 29/03 a 02/04/92, São Paulo. Revista do Instituto Florestal, Ed. especial. Vol. 4 (parte 2): 527-533. 1992.

MARTINS, F. R. Fitossociologia de Floresta no Brasil um Histórico Bibliográfico. Pesquisas - Série Botânica 40. São Paulo, 1989. MARTINS, S. V. Recuperação de Matas Ciliares. In: Martins, S. V.; Vieira, E. A. (Eds.). Aprenda fácil. Viçosa, 2001.

MARTINS, S. V. Restauração ecológica de ecossistemas degradados. Ed. UFV. Viçosa, 2012.

PASSOS, M. M. Biogeografia e Paisagem. Programa de Mestrado e Doutorado FCTUNESP/ Campos de Presidente Prudente - SP - Programa de Mestrado em Geografia UEM - Maringá-PR, 1998.

PASSOS, M. M. Por um estudo da evolução da vegetação - da pirâmide ao NDVI. Geosul. v.15, n.30, jul./dez. Florianópilis, 2000, p. 90-110.

REALEZA. Origens e Formação do Município de Realeza. Berzon Ltda. Departamento de educação, cultura e esportes, divisão de cultura. Francisco Beltrão,1995.

SERVIÇO FLORESTAL BRASILEIRO. Florestas do Brasil em resumo - 2010: dados de 20052010. Brasília, 2010.

SOUZA, M. C. Algumas considerações sobre vegetação ripária. Cadernos da Biodiversidade. v.2, n.1, p.4-10, 1999.

VARGAS, K. B. ESTUDO FITOSSOCIOLÓGICO DA MATA CILIAR DO CÓRREGo ÁGUA PEQUENA NO MUNICIPIO DE REALEZA- PR. Trabalho de Conclusão de Curso (Monografia). Universidade Estadual de Maringá. Maringá, 2009. 